\title{
CASE REPORT OF ROBOTIC INSTRUMENT-ENHANCED MITRAL VALVE SURGERY
}

Eugene A. Grossi, MD, Angelo LaPietra, MD, Robert M. Applebaum, MD, Greg H. Ribakove, MD, Aubrey C. Galloway, MD, F. Gregory Baumann, PhD, Patricia Ursomanno, RN, Bryan M. Steinberg, MD, and Stephen B. Colvin, MD, New York, NY

A case of a robot-assisted cardiac operation in the United States is reported. Minimally invasive mitral valve repair was assisted with a surgical robot under a Food and Drug Administration-guided phase I clinical trial.

Clinical summary. A 50-year-old man with severe mitral insufficiency caused by posterior leaflet prolapse underwent minimally invasive mitral valve reconstruction with the use of a robotic telemicromanipulator (ZEUS; Computer Motion Inc, Santa Barbara, Calif).* The patient was placed in a supine position on the operating table with the right arm abducted and flexed above the head. Before the patient was draped, the 3 robotic arms were clamped to the sides of the operating room table. A right anterior 6- $\mathrm{cm}$ minithoracotomy (service entrance incision) was performed in the fourth intercostal space. ${ }^{1}$ Standard minimally invasive (port access) technology was used to place the patient on cardiopulmonary bypass and induce cardioplegic arrest ${ }^{2}$. Through the service entrance, the left atrium was opened, and an intra-atrial retractor blade and cardiotomy sucker were positioned. The instruments and endoscope created an inverted triangle, allowing for proper maneuverability of the robotic instruments within the chest cavity without conflict. The left robotic instrument arm was inserted through a 5-mm screw trocar (Karl Storz, GmbH, Tuttiingen, Germany) in the lateral third intercostal space, and the right arm was placed in the medial corner of the service entrance. A $10-\mathrm{mm}, 0^{\circ}$ endoscope (Karl Storz, GmbH) was then placed in the lateral corner of the service incision. ZEUS instrument setup time was 5 minutes. A prolapsing segment of the posterior leaflet was excised, and the ZEUS Robotic System (ZRS) was used to perform a symmetric folding plasty repair of the valve (Fig 1). ${ }^{3}$ Suture knots were thrown extra-

From the Division of Cardiothoracic Surgery, Department of Surgery, New York University School of Medicine, New York, NY.

Supported in part by the Foundation for Research in Cardiac Surgery and Cardiovascular Biology.

Received for publication May 16, 2000; accepted for publication July 12, 2000.

Address for reprints: Eugene A. Grossi, MD, New York University Medical Center, 530 First Ave, Suite 9V, New York, NY 10016 (E-mail: grossi@cv.med.nyu.edu).

J Thorac Cardiovasc Surg 2000;120;1169-71

Copyright (C) 2000 by The American Association for Thoracic Surgery

0022-5223/2000\$12.00+ $0 \quad \mathbf{1 2 / 5 4 / 1 1 0 1 7 6}$

doi:10.1067/mtc. 2000.110176

*New York University Medical Center IRB H 8627-10, April 28, 2000. corporeally and positioned with a knot pusher. The leaflet reconstruction was reinforced with a rigid annuloplasty ring (Edwards Lifesciences LLC, Irvine, Calif); the annuloplasty sutures were placed with standard minimally invasive instruments. The total cardiopulmonary bypass time was 3 hours 28 minutes, and the endoluminal crossclamp time was 3 hours 2 minutes. The robotic instrumentation was used for a total of 69 minutes. Postoperative echocardiography revealed only trace mitral regurgitation, and the patient was discharged on postoperative day 3 .

Discussion. During the past 2 decades, surgical instrumentation has been adapted to endoscopic procedures, with changes in instrument shaft design and handles. However, until recently, there has been little integration of higher technology into our instruments. The recent introduction of surgical robots has greatly altered the surgical theater. In the cardiac arena the first application of this technology has naturally occurred with its adaptation to minimally invasive procedures. We have approached this new technology in an incremental fashion, so as to expand the comfort zone of the surgeon and to introduce safely this robotic technology into our clinical practice. Given that minimally invasive techniques for mitral valve operations are the preferred method at our institution, ${ }^{4}$ the past year has seen integration of a roboticaly controlled endoscopic camera (Aesop; Computer Motion, Inc, Goleta, Calif). ${ }^{5}$ This addition has not only afforded us with superior visualization, allowing for teaching, operating room team integration, and global satellite conferencing, but also has prepared us to evaluate the transition to fully endoscopic operations. ${ }^{6}$ The modular nature of this robotic system has facilitated subsequent entry of the full ZRS into the operating room. The limited dimensions of the instruments do not restrict the surgeons' and nurses' access to the patient (Fig 2).

Previous reports from outside the United States ${ }^{5}$ have demonstrated the feasibility of mitral valve operations with an instrument with 7 degrees of freedom (DOF). In this report we used an instrument with $5 \mathrm{DOF}$, as in our initial laboratory work. ${ }^{1}$ The putative relative advantage of more DOF is uncertain. Currently, evaluation of articulated instrumentation for the ZRS is ongoing in our laboratory.

This procedure initiated our clinical feasibility study of robotic instrumentation for minimally invasive mitral valve operations. Having performed more than 1200 minimally invasive heart operations, we believe that this robotic instrumentation will have a place in our armamentarium for certain procedures. Despite excellent results, limited mobility through the operative ports can affect the dexterity of the surgeon and add to the complexity of the procedure. Because minimally invasive mitral operations are performed with 


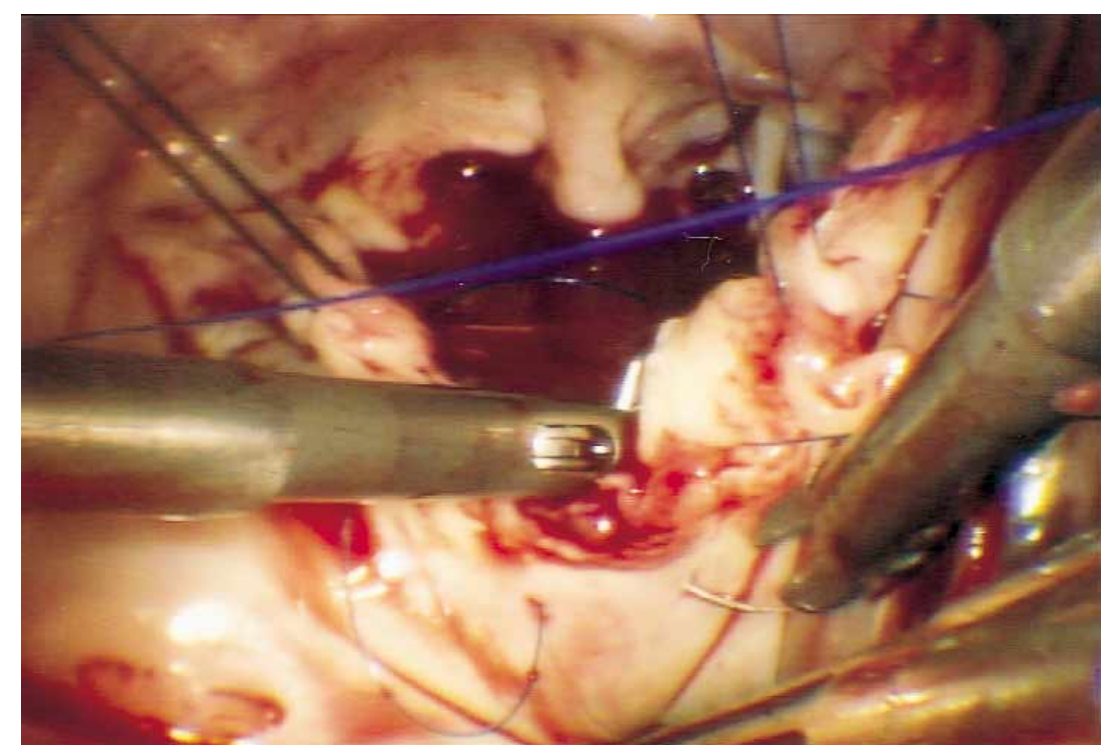

Fig 1. Surgeon console view of robotic instrument mitral valve repair.

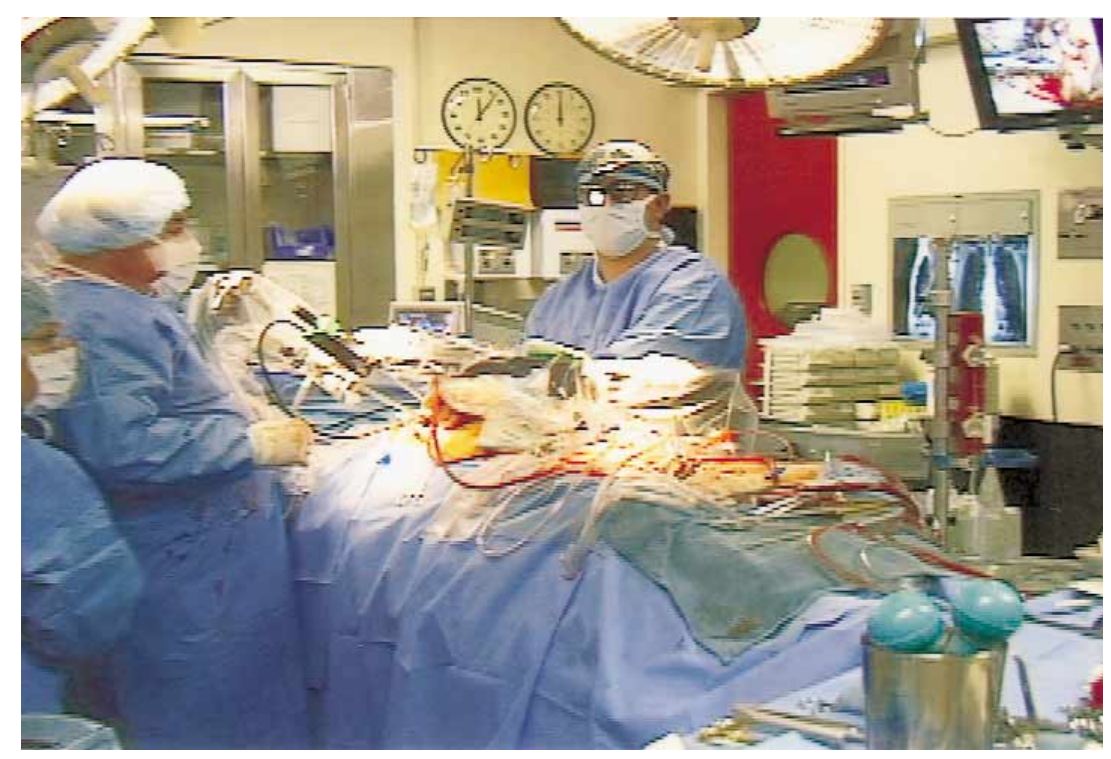

Fig 2. Robot, assistant surgeons, and scrub nurse at operating room table.

access through a long access tunnel, robotic instrumentation is ideally suited to dealing with this technical challenge, and the necessity for special long instruments may be decreased. The surgeon sitting in the surgical console has a spectacular view of his work space, sitting virtually inside the left atrium. However, although these procedural and ergonomic advantages do exist, the overall value-added benefit of this expensive technology to the patient has yet to be determined. Certainly, during this investigative phase of the procedure, the operation is prolonged. Further operative experience will demonstrate whether this technology can eventually provide comparable or reduced operative times.

The challenge for us as surgeons is not only to evaluate this technology and analyze patient outcomes but also to envision what lies ahead. Today, we are working with 2 different firstgeneration surgical robots. It is exciting to watch surgeons with different machines taking different approaches to our operative challenges. The possibilities of what we can do with second- and third-generation instruments are limited only by our imagination. 


\section{REFERENCES}

1. LaPietra A, Grossi E, Derivaux C, Applebaum R, Hanjis C, Ribakove G, et al. Robotic assisted instruments enhance minimally invasive mitral valve surgery. Ann Thorac Surg. In press.

2. Schwartz DS, Ribakove GH, Grossi EA, Buttenheim PM, Schwartz JD, Applebaum RM, et al. Minimally invasive mitral valve replacement: port-access technique, feasibility, and myocardial functional preservation. J Thorac Cardiovasc Surg 1997; 113:1022-31.

3. Grossi EA, Galloway AC, Kallenbach K, Miller JS, Esposito R, Schwartz DS, et al. Early results of posterior leaflet folding plas- ty for mitral valve reconstruction. Ann Thorac Surg 1998;65:1057-9.

4. Colvin SB, Galloway AC, Ribakove G, Grossi EA, Zakow P, Buttenheim PM, et al. Port-access mitral valve surgery: summary of results. J Card Surg 1998;13:286-9.

5. Falk V, Walther T, Autschbach R, Diegeler A, Battellini R, Mohr FW. Robot-assisted minimally invasive solo mitral valve operation. J Thorac Cardiovasc Surg 1998;115:470-1.

6. Chitwood WR Jr. Video-assisted and robotic mitral valve surgery: toward an endoscopic surgery. Semin Thorac Cardiovasc Surg 1999;11:194-205. 